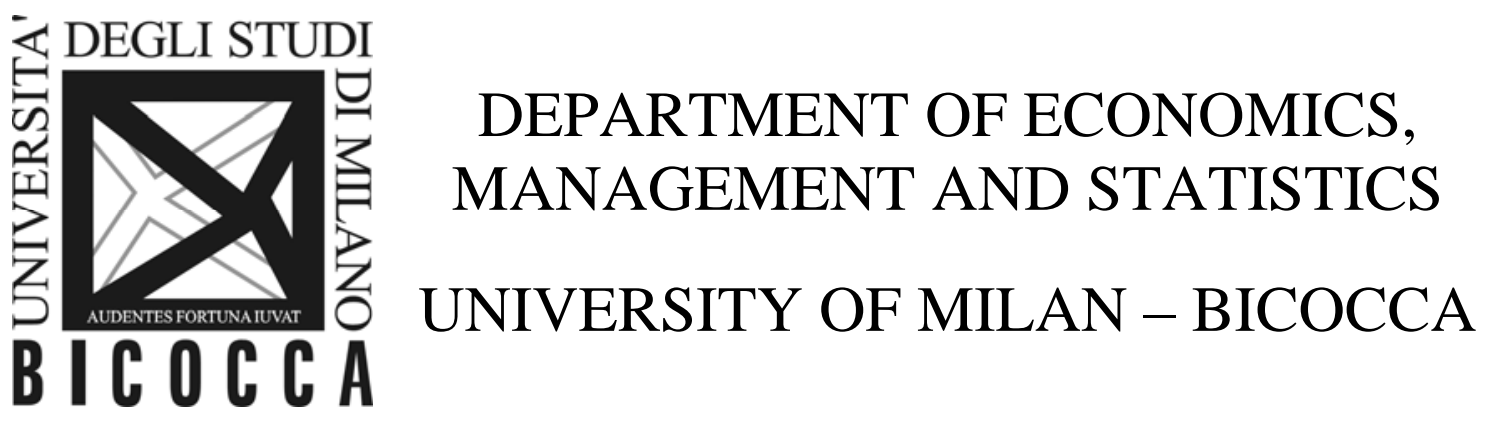

DEMS WORKING PAPER SERIES

Debt stability under entitlement spending

Floriana Cerniglia, Enzo Dia, Andrew Hughes Hallett

No. 351 - October 2016

Dipartimento di Economia, Metodi Quantitativi e Strategie di Impresa Università degli Studi di Milano - Bicocca 


\title{
Debt stability under entitlement spending
}

\author{
Floriana Cerniglia, Enzo Diał, Andrew Hughes Hallett ${ }^{\ddagger}$
}

October 5, 2016

\begin{abstract}
Economists have traditionally used a simple rule that restricts primary deficits to less than a threshold given by the interest rate-growth rate differential and existing debt level to judge fiscal sustainability. This rule derives from a single period application of the government's budget constraint. It does not allow for the predictable dynamic effects of spending liabilities, such as entitlement spending. In this paper, we derive the equivalent dynamic rule for this case. It still depends on the interest-growth rate differential, but now includes a restriction on spending growth in relation to income growth. Several new results emerge. Debt remains stable; but the rate of convergence to stability varies with different parameters. And the growth in spending has to be less than a damping factor that controls convergence. This puts a limit on spending growth. To penalize the use of unpopular taxes further limits debt and the incentive to use debt finance.
\end{abstract}

JEL classification: E62, H53, H63, I38 ;

Keywords: Sustainable public debt, primary deficit rules, fiscal space.

*Università Cattolica del Sacro Cuore. Email: floriana.cerniglia@unicatt.it
†Università degli Studi di Milano-Bicocca. Email: enzo.dia@unimib.it
†University of St Andrews and George Mason University. Email: ahughesh@gmu.edu 


\section{Introduction}

A standard complaint made by finance ministers is that limits to their freedom of fiscal action, which appear to be largely absent at the stage of policy selection or developing of a new fiscal program, typically shrink to few percentage points of discretionary action on entering office. This is due to the steady rise in precommitted entitlement spending and other implicit liabilities that preempt the revenues available.

Several papers, prominently those by Kotlikoff et al. (2005) and Davig et al. (2010), have highlighted the size of the "fiscal overhang" posed by uncovered and often unacknowledged future liabilities arising from public pension schemes, or health/social support costs, in most OECD economies. A recent paper by the IMF (2009) has put this problem into brutal relief by showing that the financial stress caused by the great financial crash of 2007-2010 was probably only about $10 \%$ of the fiscal shortfalls to be expected to arise from future agerelated spending in economies with a shrinking labor force. If that is the case, and if fiscal sustainability is a genuine objective, it makes sense to search for fiscal rules capable of ensuring stable and sustainable public finances given aging populations, shrinking labor forces and expanding future liabilities.

We have argued elsewhere that debt is superior to deficits as a target to ensure fiscal responsibility, for both theoretical and practical reasons [Hughes Hallett and Hougaard Jensen (2012), European Council (2012)]. But if debt targeting is superior, a natural question to ask is: What debt level, or debt-to-GDP ratio, should best be maintained? What deficit rule is then needed to ensure stability or fiscal sustainability in the long run? The answer to these questions involves complicated trade-offs, to balance concerns about social and intergenerational equity against economic performance and the stability of public finances [Auerbach (2009)]. 
The problem of how best to choose a target or target path for public debt also involves the question of how to account for implicit future liabilities. Typically, the spending liabilities that enter the calculation of public debt only take account of current liabilities. However, if the implicit (but nonetheless pre-committed) future liabilities due to aging populations or social support are ignored, the debt criterion will ignore the future revenues necessary to avoid default despite the capacity to cover the benefits promised to existing workers or beneficiaries.

This makes our case: we have to put the analysis of debt control and fiscal sustainability into an inter-temporal framework if we are to account for predictable demographic changes, and the predictable developments of entitlement spending or other future liabilities. We develop a dynamic version of Barro's (1979) model, where stocks matter because of non-linear cost terms. Following Bohn (1990), we then add a convex cost term for tax revenues, in order to capture the cost of an excess tax burden imposed on individuals.

In a similar way, Ghosh et al. (2013) and Checherita et al. (2013) have developed the idea of fiscal space defined as the difference between the current debt level and a debt limit or debt target beyond which debt will become unsustainable and grow exponentially. We adopt a similar approach which implies, at the country level, a trade-off between the costs imposed on the economy by the tax burden and those caused by excess debt. To this, we add a convex cost in the stock of debt on the assumption that the institutional settings of different countries impose a burden (which can be weak or strong) on excess debt. Given this setup, we study the stability of such a system and what policy or fiscal deficit rules are necessary to ensure that sustainability is achieved. That done, it is useful to examine what the steady state outcomes look like and the parameters that those outcomes principally depend upon. Finally, we analyze calibrated versions of our model, fitted to observed data from a number of lead- 
ing OECD economies, in order to examine the behavior and stability of debt in those countries

A number of new results emerge. First, in a wide range of circumstances debt remains stable under entitlement spending. But it is not guaranteed. Second, the speed of convergence back to equilibrium varies a lot with different parameter values, and most of all with the discount factor used by policy makers, as do the steady state outcomes. Understandably stability and convergence also depend on the growth in entitlement spending; in fact, stability requires the growth in spending to be less than the damping factor that controls the speed of convergence. This places a limit on spending growth: we require the growth in spending be less than that in national income, by a factor which depends on the interest rate-growth rate differential. This implies a new primary deficit rule to replace the traditional rule for debt stabilization in a single period and no entitlement spending. This is a generalization. The traditional rule implies the interest-growth rate differential is the only item of interest in each period; there is no restriction on spending growth relative to income growth. One additional insight: in this model, the quadratic cost on taxes works as an adjustment cost on debt with the result that the incentive for governments to use debt finance to smooth expenditure shocks is constrained by the cost term on tax revenues. Since the government is forward looking, and Ricardian equivalence holds, the higher the tax cost parameter, the stronger the incentive to smooth changes in the stock of debt over time. Thus deficit spending can be forced to decline.

\section{Theoretical Model}

Policy discussions of government spending are generally carried out on the basis that there is a clear-cut difference between discretionary spending on the one hand, and entitlement spending on the other for which funding is manda- 
tory unless explicit reform measures are being proposed. Entitlement spending therefore includes all those categories of expenditure that do not have to be approved annually since existing laws give different agents rights to certain benefits or services - unless a wholesale reform is called for. Two obvious examples are social security/social benefits and the compensation of employees. In order to modify the current amount or future trend of expenditure dictated by existing legislation and commitments, any changes have to be discussed and voted by Parliament. On the other hand, discretionary spending is composed of those categories of expenditures that politicians have to vote on an annual or ad hoc basis in order for them to take place. Discretionary spending also includes categories of intermediate consumption that need to be voted annually in budgetary sessions even if they then recur for several years. ${ }^{1}$

Accordingly, we model public expenditure $G_{t}$ to be composed of entitlement spending $E_{t}$ and discretionary spending $V_{t}$. Entitlement spending is an exogenous process, partially influenced by the business cycle: $E_{t}=\bar{E}+a f\left(Y_{t}\right)$, where $Y_{t}$ is the output gap and $a<0$. Thus,

$$
G_{t}=E_{t}+V_{t}
$$

The primary deficit $D_{t}$ is the difference between expenditure $G_{t}$ and tax revenues $T_{t}$, where expenditure is total general government expenditure net of interest payments, while taxes include all general government revenues: ${ }^{2}$

$$
D_{t}=G_{t}-T_{t},
$$

\footnotetext{
${ }^{1}$ The share of discretionary spending is typically about $1 / 3$ of total government spending in the OECD. A figure this size is relatively large when compared to the estimated residuals of the auto-regressive processes usually used to measure the share of expenditure that is not predetermined. However, it is much smaller than assumed in the econometric models that treat government spending to be a fully exogenous decision. See Coricelli and Fiorito (2013).

${ }^{2}$ All variables are defined as ratios with respect to income
} 
while the debt-to-GDP ratio $B_{t}$ varies over time because of the primary deficit, interest payments, and the growth of nominal GDP:

$$
B_{t}=\left(1+r_{t-1}-\rho_{t-1}\right) B_{t-1}+D_{t}
$$

where $r_{t}$ is the average interest rate paid on debt and $\rho_{t}$ is the rate of growth of nominal output. In each period taxes are thus equal to:

$$
T_{t}=G_{t}-B_{t}+\left(1+r_{t-1}-\rho_{t-1}\right) B_{t-1} .
$$

To keep the model tractable we assume that discretionary spending is financed with tax revenues (but borrowing is allowed to cover entitlement spending):

$$
V_{t}=\tau T_{t}
$$

and thus

$$
T_{t}=\psi\left[E_{t}-B_{t}+\left(1+r_{t-1}-\rho_{t-1}\right) B_{t-1}\right]
$$

where $\frac{1}{1-\tau}=\psi$, and $0<\tau<1$. Since discretionary spending is a small share of the total this assumption does not impose any implausible restrictions. The problem is now simpler because the choice of funding by taxation or debt is made for a given or predicted composition of expenditure, between discretionary and entitlement spending.

Although Eq. 6 is standard, this formulation highlights that as long as the costs imposed by raising taxes are not linear, any convex cost on $T_{t}$ generates both an adjustment cost on the stock of debt. Together, these costs will impose a ceiling on debt. Eq. 6 can in fact be rewritten as

$$
T_{t}=\psi\left[E_{t}-\Delta B_{t}+\left(r_{t-1}-\rho_{t-1}\right) B_{t-1}\right] .
$$


As a consequence, whenever non-linear costs functions for taxes apply, the problem becomes dynamic, even without assuming further explicit non-linear cost functions for the stock of debt or its adjustment. Our modelling strategy is therefore different from the standard version that analyzes the stock public debt as the result of a sequence of period by period independent budget constraints, without recognizing the intertemporal elements.

We assume that the objective function of the policy maker is to provide the chosen expenditures while minimizing minimizing taxes and interest costs. Entitlement spending generates linear benefits that we normalize to one, discretionary spending generates both linear and convex benefits:

$$
G O F=E_{t}+\zeta V_{t}+\frac{\delta}{2}\left(V_{t}\right)^{2}-\nu T_{t}-\frac{\varphi}{2}\left(T_{t}\right)^{2}-\frac{\iota}{2}\left(B_{t}\right)^{2}-r_{t} B_{t} .
$$

Policymakers maximize objective function (8), subject to equation (6) and equations that define the stochastic process of expenditure, interest rates, and GDP growth. For simplicity, we model the latter as exogenous $\operatorname{AR}(1)$ processes in our basic model:

$$
\begin{aligned}
& E_{t+1}=E_{t}+\eta_{t+1}, \\
& r_{t+1}=r_{t}+\epsilon_{t+1}, \\
& \rho_{t+1}=\rho_{t}+\theta_{t+1} .
\end{aligned}
$$

The non-linear cost terms on both taxes and debt may capture either the distortionary effects of taxation and debt on income, or political economy restrictions on government behavior. As a consequence, the policy-maker chooses the composition of tax revenues and debt to minimize its costs given an expected stochastic path for expenditure, GDP growth, and interest costs.

Defining $d$ as the discount factor, the Lagrangian form of the problem is the 
following:

$$
\begin{array}{r}
\Lambda=d^{t}\left\{E_{t}-\gamma T_{t}-\frac{\alpha}{2}\left(T_{t}\right)^{2}-\frac{\iota}{2}\left(B_{t}\right)^{2}-r_{t} B_{t}+\right. \\
\left.\mu_{t}\left[T_{t}-\psi E_{t}+\psi B_{t}-\psi\left(1+r_{t-1}-\rho_{t-1}\right) B_{t-1}\right]\right\},
\end{array}
$$

where

$$
\gamma=\nu-\zeta \tau, \quad \text { and } \quad \alpha=\varphi-\delta \tau^{2} . \quad 3
$$

Tax revenues are a control variable, while debt is a state variable. ${ }^{4}$ The first order conditions are the following

$$
\begin{gathered}
\frac{\partial \Lambda}{\partial T_{t}}=-\gamma-\alpha T_{t}+\mu_{t}=0 . \\
\frac{\partial \Lambda}{\partial B_{t}}=-\iota B_{t}-r_{t}+\psi \mu_{t}-d \psi\left(1+r_{t}-\rho_{t}\right) \mu_{t+1}=0 . \\
\mu_{t}=\gamma+\alpha T_{t} .
\end{gathered}
$$

Defining $\beta=\frac{\iota}{\psi}$ and $v=\frac{1}{\psi}$, we get

$$
d\left(1+r_{t}-\rho_{t}\right) \mu_{t+1}=\mu_{t}-\frac{\iota}{\psi} B_{t}-\frac{1}{\psi} r_{t}=\mu_{t}-\beta B_{t}-v r_{t}
$$

Note that, since $\psi>1$, it follows that $\iota<\beta$ and $v<1$. Substituting the value

\footnotetext{
${ }^{3}$ The term in $\alpha$ represents the non-linear cost of taxes net of benefits obtained from discretionary spending, but these benefits are multiplied by $\alpha^{2}$. For an average of $\alpha=0.3$, as calculated across OECD economies over the past four decades, any benefits generated by discretionary spending is multiplied by a factor of 0.09 . We therefore treat $\alpha$ as the cost of using taxes in the rest of our analysis, although highly non-linear benefits from discretionary spending may in fact dominate in certain instances. Similarly, the $\gamma$ term measures the linear cost of taxes net of benefits from discretionary spending. Given this formulation, we may expect $\alpha$ and $\gamma$ to vary substantially in countries with different institutional settings. Furthermore in certain instances, for example in crisis periods, these underlying parameter values may change over time. As discussed by Hughes Hallett (1979), when recovering the underlying parameters from empirical estimates the local validity of the results must taken in to account.

${ }^{4}$ We treat $\tau$ as a predetermined parameter, since it would be too complicated to obtain a closed form solution if $\tau$ is an endogenous variable.
} 
for $\mu_{t}$ from Eq. 16 in Eq. 17, we obtain:

$$
\left(1+r_{t}-\rho_{t}\right) T_{t+1}=\frac{1}{d} T_{t}-\frac{1}{d \alpha}\left[-\gamma(1-d)+(v+d \gamma) r_{t}-d \gamma \rho_{t}+\beta B_{t}\right] .
$$

We can also substitute the value of $T_{t}$ from Eq. 2:

$$
\begin{array}{r}
\left(1+r_{t}-\rho_{t}\right)\left(G_{t+1}-D_{t+1}\right)=\frac{1}{d} G_{t}-\frac{1}{d} D_{t} \\
-\frac{1}{d \alpha}\left[-\gamma(1-d)+(v+d \gamma) r_{t}-d \gamma \rho_{t}+\beta B_{t}\right],
\end{array}
$$

and

$$
\begin{array}{r}
\Delta B_{t+1}=\left(1+r_{t}-\rho_{t}\right) G_{t+1}-\frac{1}{d} G_{t}-\left(r_{t}-\rho_{t}\right) B_{t+1}+\left[\left(r_{t}-\rho_{t}\right)^{2}+2\left(r_{t}-\rho_{t}\right)\right] B_{t}+ \\
\frac{1}{d} B_{t}-\frac{1}{d}\left(1+r_{t-1}-\rho_{t-1}\right) B_{t-1}+\frac{1}{d \alpha}\left[-\gamma(1-d)+(v+d \gamma) r_{t}-d \gamma \rho_{t}+\beta B_{t}\right] .
\end{array}
$$

We have now obtained a law of motion of government debt that shows how any expenditure shock is entirely absorbed by new debt issuance. Both the response of new issuance to the existing level of the stock of bonds and to market interest rates are functions of the relative weight of the non-linear cost of debt and taxes. For higher levels of the tax parameter $\alpha$ the impact of interest rates and the past stock of debt declines. The impact of interest rates rises with the linear cost term $\gamma$, while the impact of the past stock of debt is large for larger values of the parameter $\beta$ measuring the convex cost on the stock of debt.

The second order difference equation in $B_{t+1}$ (which includes the debt implicit in the anticipated deficits $D_{t+1}$ and $D_{t}$ ) cannot be solved with standard techniques (as those proposed by Sargent (1979)) because $r_{t}$ is part of the intercept term, but also of the slope, and the roots of the solutions are thus time-varying. But it can be estimated. 


\subsection{Solvency rule}

Equation 20 can be rewritten as:

$$
\begin{gathered}
\Delta B_{t+1}=\left(1+r_{t}-\rho_{t}\right) G_{t+1}-\frac{1}{d} G_{t}+\left(r_{t}-\rho_{t}\right)\left(1+r_{t-1}-\rho_{t-1}\right) B_{t-1} \\
-\left(r_{t}-\rho_{t}\right) \Delta D_{t+1}+\frac{1}{d} D_{t}+\frac{1}{d \alpha}\left[-\gamma(1-d)+(v+d \gamma) r_{t}-d \gamma \rho_{t}+\beta B_{t}\right]
\end{gathered}
$$

which in turn yields a rule which defines the primary surplus sufficient to stabilize debt:

$$
\begin{array}{r}
-D_{t}=\left[d\left(1+r_{t}-\rho_{t}\right) G_{t+1}-G_{t}\right]+d\left(r_{t}-\rho_{t}\right)\left(B_{t}-D_{t+1}\right)+ \\
+\frac{1}{\alpha}\left[-\gamma(1-d)+v r_{t}+d \gamma\left(r_{t}-\rho_{t}\right)+\beta B_{t}\right] .
\end{array}
$$

where $v=1-\tau$. This rule defines a threshold above which the primary surplus will reduce the debt ratio, and below which debt increases. It is however, quite different from the standard textbook rule which, in this notation, would be $-D_{t}=\left(r_{t}-\rho_{t}\right) B_{t}$. In fact equation (22) contains three terms. The first represents the discounted growth adjusted increase in total public spending relative to national income. The second is the counterpart to the standard textbook rule, but it is discounted and adjusted for the expected/planned surplus next period. The last term represents all the preference factors (and post-tax interest rate) that arise automatically because, as soon as we enter a dynamic framework, we need to account for intertemporal optimizing behavior: that is, for the choice between raising taxes now or extending debt/taxing later to financing current and future spending liabilities. The trade-off between using taxes vs. debt is very likely to dominate (22) since the remaining terms will be small compared to the $(\beta / \alpha) B_{t}$ term.

The result is a significant extension of the tradition criterion for fiscal sus- 
tainability, as is most clearly seen from the special case when $r_{t}=\rho_{t}$ :

$$
-D_{t}=d G_{t+1}-G_{t}+\frac{1}{\alpha}\left[-\gamma(1-d)+v r_{t}+\beta B_{t}\right] .
$$

The implication of (22) is that the old period-by-period criterion is no longer sufficient to ensure sustainable debt (public finances) once entitlement spending enters the story. Instead, we need to impose a condition that public spending shall not grow faster than national income by a certain permitted amount and the effect of the preferences for taxing now vs. increasing debt and taxing later from expected growth. The usual period-by-period rule is therefore neither necessary, nor sufficient for fiscal stability in an economy with entitlement spending.

This shows that the primary surplus should match any expected, discounted increase in expenditure plus an extra term involving the interest rate and nonlinear costs of debt $\beta$ divided by the non-linear cost of changing taxes, $\alpha$.

When the policy maker has a strong aversion to debt, so $\beta$ is larger, or when interest costs are large, the primary surplus required is larger. By contrast, the higher the distortions caused by higher tax revenues relative to income, the lower is the primary surplus required since debt becomes a more attractive tool to smooth any expenditure shock.

\section{$2.2 \quad$ Stability conditions}

For the purposes of analyzing debt sustainability, Eq. (21) can be reformulated to give a form that both incorporates the cross-parameter restrictions which are implied by our theoretical model, and avoids imposing the artificial simplifying assumption that $r_{t}-\rho_{t}=\kappa$ is constant over time. The data clearly shows that this assumption is not satisfied in any OECD economy. To accomplish this, we simply rewrite Eq. (21) as follows: 


$$
\begin{gathered}
\Delta B_{t+1}=a_{0}+a_{1} G_{t+1}-a_{2} G_{t}+a_{3} B_{t-1} \\
-a_{4} \Delta D_{t+1}+a_{5} D_{t}+a_{6} B_{t}+a_{7} r_{t}+a_{8} \rho_{t}
\end{gathered}
$$

where

$$
\begin{aligned}
& a_{0}=\frac{\gamma(1-d)}{d \alpha} \quad a_{1}=1+r_{t}-\rho_{t} \quad a_{2}=-\frac{1}{d} \\
& a_{3}=\left(r_{t}-\rho_{t}\right)\left(1+r_{t-1}-\rho_{t-1}\right) \quad a_{4}=-\left(r_{t}-\rho_{t}\right) \quad a_{5}=\frac{1}{d}=a_{2} \\
& a_{6}=\frac{\beta}{d \alpha} \quad a_{7}=\frac{v+d \gamma}{d \alpha} \quad a_{8}=-\frac{\gamma}{\alpha} .
\end{aligned}
$$

The reformulated Equation (24) also allows us to look at fiscal stability, and hence fiscal sustainability, directly. Using (2) the debt dynamics that follow ${ }^{5}$

$$
\begin{array}{r}
\left\{B_{t+1}-G_{t+1}-\left(r_{t}-\rho_{t}\right)\left[\left(1+r_{t-1}-\rho_{t-1}\right) B_{t-1}\right]\right\}= \\
a_{0}+a_{2} T_{t}+\left(1+a_{6}\right) B_{t}+a_{7} r_{t}-a_{8} \rho_{t}+\left(r_{t}-\rho_{t}\right)\left[\Delta T_{t+1}+G_{t}\right]+\epsilon_{t}
\end{array}
$$

will be stable if and only if the fiscal system

$$
\begin{array}{r}
{\left[\begin{array}{l}
B_{t+1} \\
B_{t}
\end{array}\right]=\left[\begin{array}{cc}
1+a_{6} & c \\
1 & 0
\end{array}\right]+\left[\begin{array}{c}
B_{t} \\
B_{t-1}
\end{array}\right]+a_{0}+a_{2} T_{t}+\left(1+a_{6}\right) B_{t}+} \\
a_{7} r_{t}-a_{8} \rho_{t}+\left(r_{t}-\rho_{t}\right)\left[\Delta T_{t+1}+G_{t}\right]+\epsilon_{t},
\end{array}
$$

has roots inside the unit circle, where $c=\left(r_{t}-\rho_{t}\right)\left(1+r_{t-1}-\rho_{t-1}\right)$ and where $T_{t}$ are choice variables at each $t$. The stability of the fiscal system is controlled

\footnotetext{
${ }^{5}$ Notice that the distinction sometimes drawn between global stability and saddle path stability does not apply here: a first order lead-lag (forward, backwards) dynamic system is equal to a renormalized second order (backwards) difference equation provided the coefficients on the lead term are invertible [Fisher and Hughes Hallett (1988)]. This is the case in (18).
} 
by the roots of $(26), \lambda_{1,2}$ obtained by solving

$$
\lambda^{2}-\left(a_{6}+1\right) \lambda-c=0
$$

where $a_{6}>0$, by definition given the policy cost function in (8). Hence,

$$
\lambda_{1,2}=\frac{1}{2}\left\{a_{6} \pm \sqrt{\left(a_{6}+1\right)^{2}+4 c}\right\}=\frac{a_{6}+1}{2} \pm \sqrt{\left(\frac{a_{6}+1}{2}\right)^{2}+c} .
$$

Note that $c$ will have the sign of $r_{t}-\rho_{t}$ in all but quite exceptional circumstances since $r_{t-1}-\rho_{t-1}$ will measure only a few percentage points and therefore be a good deal less than unity. That means there are now just two cases to consider:

1. $r_{t}-\rho_{t}<0$, so $c<0$. The positive root from (28), $\lambda_{1}$ will be in the unit circle if

$$
\sqrt{\left(\frac{a_{6}+1}{2}\right)^{2}+c}<1-\frac{a_{6}+1}{2} \quad \text { that is, if } \quad c<-a_{6} .
$$

We need, in addition, to impose that the right hand side is positive: 1 $\frac{a_{6}+1}{2}>0$. This requires $a_{6}<1$, or $\beta<d \alpha$, given the definition of $a_{6}$. This is a necessary condition; the rest of the inequality, $c<-a_{6}$, is sufficient. This additional restriction is interesting since, with weak or no discounting $(d=1)$, it implies that policymakers have to worry more about taxes than debt. Intuitively: if I don't discount, I have to force taxes to be consistent with stability. The debt that then follows will be stable. But if I do discount, I can loosen taxes to some extent because the mild debt instability that may follow later on will be discounted away. However when the reverse inequality holds, the stability condition can never be satisfied.

Conversely, with full discounting $(d=0)$, the only thing that matters is 
the debt level (the term in $\gamma$, since $\beta \leq 0$ would then be necessary). This is what we see in the traditional period-by-period primary surplus rule. But this case implies $a_{6}$ is infinite, so the system's roots are infinity and zero, and its dynamics have become a random walk. In that case, the system is unstable unless policies are set to exactly offset each of the shocks as they arise - as in the standard period-by-period primary surplus rule. This is the result that makes the case for writing this paper: you must plan for the future if you want to maintain fiscal sustainability under entitlement spending, tax smoothing, or persistence in the (gross) deficit, and other forms of fiscal policy dynamics.

The rest of the stability condition at (28) may be rewritten as:

$$
\frac{\beta}{\alpha}<\left(\rho_{t}-r_{t}\right)\left[1+r_{t-1}-\rho_{t-1}\right] d .
$$

This says that stability is always possible as long as growth exceeds interest payments $\left(\rho_{t}>r_{t}\right)$. Moreover the more that growth rates exceed interest rates, the more that you can rely on debt control (in practice, fiscal consolidation or austerity) rather than active tax interventions to provide that stability. But if the growth rate is only marginally above interest payments, then you need to base your policies on active tax changes rather than debt control or austerity policies.

Finally, notice that the negative root in (28), $\lambda_{2}$, is in the unit circle if $c<a_{6}+2$. That condition is automatically satisfied since the right hand side is positive.

2. $r_{t}-\rho_{t}>0$, so $c>0$. In this case, the dynamics implied by (20) and (26) are always unstable since (28) implies $\lambda_{1}>1+a_{6}>1$. So at least one root being greater than unity implies instability and unsustainable fiscal 
policies in all situations.

\section{Comments:}

1. It is worth noting that stability in this type of model involves roots that are based on time-varying parameters in the equation of motion, (20) or (21), and hence the policy rule (22). To be fair, this was also the case in the standard rule above, $-D_{t}=\left(r_{t}-\rho_{t}\right) B_{t}$, but is seldom remarked upon as the latter is usually derived for one period at a time. This just means that, if you operate a fixed rule, you may have periods of temporary instability requiring periods of greater stabilization to keep the economy on a stable path overall.

2. Notice also $\frac{\beta}{\alpha}$ in (30) measures the sensitivity of the marginal cost of debt relative to the level of debt, compared to the sensitivity of the marginal cost of taxes relative to the level of tax. But it also measures the trade-off between the marginal cost of debt and the cost imposed by the volatility of debt as the stock of debt varies. Since the non-linear cost of taxes generates implicitly an adjustment cost on the stock of debt, the parameter $\alpha$, measures its impact in both cases.

3. Finally in the stable case, $r_{t}-\rho_{t}<0$, the stability condition (30) can be satisfied even if $\frac{\beta}{\alpha}<0$. The model can therefore have a stable equilibrium even if the convex cost of debt is zero because the convex cost on taxes generates an adjustment cost on the stock of debt. Hence debt will have a natural ceiling in steady-state if there are costs to using the tax instrument. Put differently, because of Ricardian equivalence, higher debt now implies higher taxes in the future, generating greater correction costs in the future. It therefore pays to restrain debt earlier rather than later-implying a ceiling for debt in steady state. 
The diagram of Figure 1 displays the value of $\kappa$ for several countries over the 1960-2014 period. While there is substantial variability both across countries and across time, it clearly emerges that the values of $\kappa$ were substantially negative during the first decades of the sample, to become positive in the second part. As a consequence, while debt could be stable during the first half-sample in most countries, it has become unstable in recent decades. If the Blanchard-

Figure 1: This diagram displays the value of $\kappa$ for several countries over the 1960-2014 period.

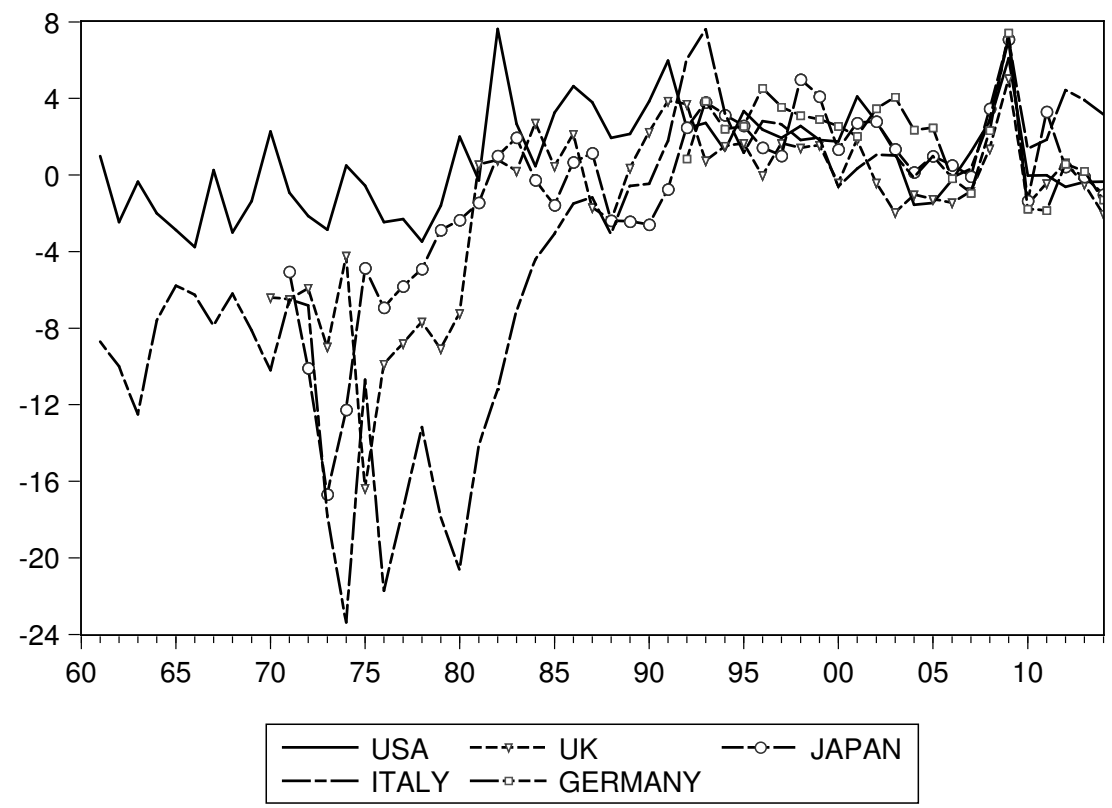

Kahn conditions apply, so that one of the roots is smaller than one, while the other is larger, we can study what happens when debt becomes unstable. The Blanchard-Kahn conditions require that $\kappa+\frac{1}{d(1+\kappa)}+\frac{\beta}{d \alpha(1+\kappa)}>\frac{1}{d}$. In the limiting case of no depreciation and $\kappa=0$, the condition becomes $\frac{\beta}{\alpha}>0$. In general, a saddle-path equilibrium requires a positive value of $\frac{\beta}{\alpha}$ for values of $\kappa$ in the range between $0 \leq \kappa \leq \frac{1-d}{d}=k^{* *}$, negative otherwise. For standard 
values of the $d$, such as 0.98 or 0.95 , the respective values are $k^{* *}=0.02041$ and $k^{* *}=0.05263$. As a consequence, when $\kappa$ is positive and debt is unstable, saddle-path stability, involving the existence of a single stable trajectory for debt, requires a positive value of $\kappa$ for in interval of $\kappa$ values that becomes larger for smaller values of the discount factor. When the policy maker discounts the future heavily and $\kappa$ becomes positive, any credible stabilization policy requires both $\alpha>0$ and $\beta>0$.

\section{$2.3 \quad$ Steady-state}

In steady state, the interest-growth rate differential, $\kappa=r_{t}-\rho_{t}$, will be constant over time. The level of taxes in steady state can then be be obtained from the dynamic balance sheet constraint, Equation 4

$$
T=E_{t}+\kappa B .
$$

The corresponding steady state level of debt can be obtained from Equation 21 with some simple manipulations:

$$
\begin{array}{r}
B-\left[1+\kappa+\frac{\alpha+\beta}{d \alpha(1+\kappa)}\right] B+\frac{1}{d} B= \\
G-\frac{1}{(1+\kappa) d} G+\frac{1}{d \alpha(1+\kappa)}[\gamma(1-d)+r+\gamma \kappa] .
\end{array}
$$

It is easy to verify that, in the limiting case of no discounting and $\kappa=0$, the steady state value of debt is $B=-\frac{r}{\beta}$, which is always negative for positive values of $\beta$. But more generally, if we define $a=\frac{1}{d}-\kappa-\frac{\alpha+\beta}{d \alpha(1+\kappa)}=$ $\frac{\alpha(1+\kappa)-d \alpha \kappa(1+\kappa)-\alpha-\beta}{d \alpha(1+\kappa)}=\frac{\alpha \kappa-d \alpha \kappa(1+\kappa)-\beta}{d \alpha(1+\kappa)}$ and $c=-\gamma(1-d)+r+\gamma \kappa$, the steadystate equilibrium can be expressed as:

$$
B=\frac{(1+\kappa) d-1}{[\alpha \kappa-d \alpha \kappa(1+\kappa)-\beta] \alpha} G+\frac{c}{\alpha \kappa-d \alpha \kappa(1+\kappa)-\beta} .
$$


A necessary condition for the denominator of the parameters of the right to be positive is:

$$
\frac{\beta}{\alpha}<\kappa[1-d(1+\kappa)]
$$

When this condition is not satisfied the denominators are negative, and the second term of of Equation 32 is always negative. To get positive values of $B$ (net debt), the first term of the sum must be positive and large enough to overcome the second. For this to be the case $d<\frac{1}{1+\kappa}$ is a necessary condition.

For positive values of $\kappa$, and $d<\frac{1}{1+\kappa}$, the policy maker must thus discount the future very heavily in order to hold debt in steady-state. But in this case stability requires substantial non-linear costs $\frac{\beta}{\alpha}$. Is that realistic in practice?

Table 1 displays an example of such a scenario, assuming steady state values for interest costs of 5 percent and an expenditure share of GDP equal to 0.4375. In this case we get sensible results, but the results change substantially with

Table 1: Steady state values for selected parameters

\begin{tabular}{|c|c|c|c|c|c|c|}
\hline Parameter values & $\gamma=0.5$ & $\alpha=0.1$ & $\beta=0.001$ & $\kappa=0.01$ & $d=0.955$ & \\
\hline Steady state values & & $\mathrm{T}=0.444$ & & $\mathrm{~B}=0.63$ & & $\mathrm{G}=0.4375$ \\
\hline
\end{tabular}

variations of the discount rate. For example a discount factor $d=0.96$ generates a steady-state value of debt of 0.35 , while a $d=0.95$ generates a steady-state value of debt of 0.91 . On the other hand the variations of the equilibrium values for changes of all other variables are far less dramatic. In particular equilibria with positive but reasonable values of debt are compatible with a large range of positive values of $\kappa, \alpha$ and $\beta$ values. For example for $\alpha=0.5$ and $d=0.95$ steady-state debt $B$ moves to 1.64. But for larger values of $\alpha$, the results vary a lot with small changes of the discounting factor. 
By way of contrast, the condition the condition $d<\frac{1}{1+\kappa}$ is always satisfied for negative values of $\kappa$, and steady state levels of debt are positive for a large range of parameters settings: see Table 2 . In this type of equilibrium the steadystate value of taxes is lower than that of expenditure; and, as the value of $\kappa$ grows more negative, the sustainable steady-state level of debt becomes larger. In fact, the equilibrium level of debt may be substantial for even small values of $\alpha$. With $\kappa=-0.02, \alpha=0.1$, and $\beta=0.01$, for example, the steady-state value of debt is $B=0.47$. If the cost of varying taxes is substantial, $\alpha=0.5$, $B$ remains positive even if there is a high value to issuing debt such as $\beta=0.2$. In other words, the optimal steady state value of debt may be positive even when the policy maker is strongly averse to debt, if the cost of varying taxes is large. But when $\beta=0$, as in the table, the results become sensitive to the value $\kappa$. For example, $\kappa=-0.0055$ moves the steady-state level of debt to 2.51 ; but reducing it to $\kappa=-0.0053$ yields a value of -0.33 .

Table 2: Steady state values

\begin{tabular}{lccccc}
\hline Parameter values & $\gamma=0.5$ & $\alpha=0.5$ & $\beta=0$ & $\kappa=-0.0054$ & $d=0.987$ \\
\hline Steady state values & & $\mathrm{T}=0.431$ & & $\mathrm{~B}=1.13$ & \\
\hline
\end{tabular}

\subsection{Solution}

When the expected value of $\kappa$ is constant, and both the Blanchard-Kahn conditions and suitable transversality conditions hold, the final solution can be obtained with standard techniques as:

$$
\begin{array}{r}
B_{t}=\lambda_{1} B_{t-1}-\lambda_{1} \sum_{i=0}^{\infty}\left(\frac{1}{\lambda_{2}}\right)^{i}\left\{G_{t+i+1}-\frac{1}{d(1+\kappa)} G_{t+i}\right. \\
\left.+\frac{v+d \gamma}{d \alpha(1+\kappa)} r_{t+i}+\frac{\gamma(1-d)+d \gamma \kappa}{d \alpha(1+\kappa)}\right\} .
\end{array}
$$


The necessary transversality condition requires the sequences for $\left\{\Delta G_{t+i}\right\},\left\{G_{t+i}\right\}$, and $\left\{r_{t+i}\right\}$ to be exponential order of less than one to ensure a finite equilibrium is defined. In this lead-lag of the model, $\lambda_{1}$ indicates the root of the characteristic equation that is smaller than one, while $\lambda_{2}$ indicates the root that is larger than one. The forward looking part of the solution depends on the intercept term $\kappa$ and the exogenous processes of expenditure and interest payments. Thus higher current or future interest rates have to induce a reduction of the stock of debt. That means policymakers will react to any shocks by reducing debt and increasing taxes today in order to reduce the burden of future taxes and debt.

To demonstrate the role of future expenditure shocks here, we can start from a hypothetical case where $d \alpha(1+\kappa)=1$. In this case, the level of debt would be changed only by a systematic trend in the growth of expenditure that would induce a lower equilibrium level of debt. With positive values for $\kappa$, and $d<(1+\kappa)$, a necessary condition to have positive debt in steady-state, the coefficient on the lagged value of expenditure has to be smaller than one. If that is true, even if the expenditure process is I(1), the impact on debt of an expenditure shock is not permanent. Instead, it dies out with a speed that is higher, the lower is the discount factor. But when $\kappa$ is negative, expenditure shocks generate an increase in the level of debt that is higher, the larger is the absolute value of $\kappa$. To summarize the results: when $\kappa \geq 0$ the model predicts that any expenditure shock generates a long-lasting, if not permanent, reductions of the stock of debt. For negative values of $\kappa$, expenditure shocks are accommodated with temporary, but persistent, increases in the stock of debt, as the long-term benefits due to the lower cost of debt per unit of output offset the costs of higher debt and future taxes (Tables 1 and 2).

The equilibrium value of debt is negatively related to expected future interest rates. The impact of the interest rate grows with the value of $v$ and with the 
linear cost of using taxes, $\gamma$. Since $v$ is a decreasing function of the parameter $\tau$, measuring the size of entitlement spending, it follows that the impact of interest rates on the equilibrium value of debt crucially depends on the share of entitlement spending.

Finally, the intercept term suggests that since debt imposes higher future taxes, when taxes generate large costs $\gamma$ the expected equilibrium level of debt becomes lower.

For large values of the non-linear cost of taxes $\alpha$, the impact of interest rate shocks and of the cost of taxes $\gamma$ becomes smaller. Overall larger values of $\alpha$ are associated with a lower debt, as changes in the tax level induce heavy costs to the policymaker, making debt relatively less appealing, since debt induces higher taxes in the future.

\section{$3 \quad$ Impulse response functions}

The next step is to check if this model generates plausible paths and steady state responses to fiscal and monetary innovations, both in theory (qualitatively) and in practice (numerically), that match the general experience of the OECD economies. We do so for a constant value of $\kappa$ and assuming parameter values that respect the Blanchard-Kahn conditions. We calibrate the model for a subsample of five countries, United States, United Kingdom, Japan, Germany, and Italy. ${ }^{6}$

In this exercise we calibrate the model under the assumption that the observed level of the variables in the year 2014 is the steady state value resulting from the model. We then generate impulse response functions following shocks to the exogenous variables of a magnitude similar to those observed in recent

\footnotetext{
${ }^{6}$ The data on debt for Europe are those based on the Maastricht criterion provided by the OECD, while those of USA and Japan are from the IMF. All other data are from the OECD.
} 
decades. For the purposes of illustration, we start from the levels of expenditure, debt and interest payments observed in 2014 as if they were steady-state values of the variables, and we calibrate the model assuming a constant value of $\kappa$, equal to the the time-series average value that we observe in the second part of the sample, which is much closer to the most recent values than the average taken over the sample as a whole. To evaluate the performance of the model, we leave the steady-state value of taxes free, and compare the theoretical values of taxes predicted by the model for each country with the values observed in the data for the year 2014 .

For each country we estimate the stochastic processes of the exogenous variables, interest payments and the expenditure to GDP ratio (Eq. 9 and 10 respectively), as the $\mathrm{AR}(1)$ processes, displayed in Tables $3,4,5,6$, and 7 . In the calibration, we use the value of the coefficient of persistence obtained from the estimates, while we choose the value of the intercept of the stochastic processes in order to match in steady-state the value of yearly interest payments and expenditure in 2014. We match the historical volatility of the variables by using the time-series standard deviations of the variables.

Table 3: Properties of selected variables for the United States of America

\begin{tabular}{lccccc}
\hline Variable & $\mu$ & $\mu 1960-1987$ & $\mu 1988-2014$ & $\sigma$ & $C . V$. \\
\hline Public Expenditure & 0.314 & 0.299 & 0.331 & 0.03 & 0.09 \\
Interest payments & 0.074 & 0.082 & 0.066 & 0.024 & 0.32 \\
$\kappa$ & 0.008 & -0.0015 & 0.018 & 0.026 & 3.25 \\
\hline Estimated Ar $(1)$ processes & \multicolumn{5}{c}{ Stationarity } \\
\hline$E_{t}=0.030+0.909 * E_{t-1}$ & & $\mathrm{I}(0)$ & $\mathrm{I}(1)$ \\
$r_{t}=0.00019+0.994 * r_{t}$ & & \multicolumn{5}{c}{} \\
\hline
\end{tabular}

Notes: Sample: 1960-2014. Analysis of stationarity conducted by means of Advanced Dickey Fuller and Phillips-Perron unit root tests. $\mu$ is the mean value, $\sigma$ the standard deviation, and C.V. the coefficient of variation of the variables.

We impose some parameters symmetrically for all countries. In particular, $\gamma$ is set at 0.5. This is in line with the results of Barro and Redlick (2011) 
Table 4: Properties of selected variables for Japan

\begin{tabular}{lccccc}
\hline Variable & $\mu$ & $\mu 1960-1987$ & $\mu 1988-2014$ & $\sigma$ & $C . V$. \\
\hline Public Expenditure & 0.298 & 0.254 & 0.343 & 0.06 & 0.20 \\
Interest payments & 0.037 & 0.056 & 0.026 & 0.020 & 0.54 \\
$\kappa$ & -0.008 & -0.041 & 0.014 & 0.045 & 5.96 \\
\hline Estimated Ar(1) processes & & Stationarity \\
\hline$E_{t}=0.010+0.979 * E_{t-1}$ & & $\mathrm{I}(0)$ & $\mathrm{I}(0)$ \\
$r_{t}=-0.00068+0.993 * r_{t}$ & & \multicolumn{5}{c}{} \\
\hline
\end{tabular}

Notes: Sample: 1960-2014 for Public Expenditure, 1971-2014 for Interest Payments. Analysis of stationarity conducted by means of Advanced Dickey Fuller and Phillips-Perron unit root tests. $\mu$ is the mean value, $\sigma$ the standard deviation, and $C . V$. the coefficient of variation of the variables.

Table 5: Properties of selected variables for Germany

\begin{tabular}{lccccc}
\hline Variable & $\mu$ & $\mu 1960-1987$ & $\mu 1988-2014$ & $\sigma$ & $C . V$. \\
\hline Public Expenditure & 0.437 & - & 0.437 & 0.02 & 0.05 \\
Interest payments & 0.048 & - & 0.048 & 0.016 & 0.33 \\
$\kappa$ & 0.020 & - & 0.020 & 0.023 & 1.15 \\
\hline Estimated Ar $(1)$ processes & & Stationarity \\
\hline$E_{t}=0.26+0.415 * E_{t-1}$ & & $\mathrm{I}(0)$ & $\mathrm{I}(0)$ \\
$r_{t}=-0.00167+0.991 * r_{t}$ & &
\end{tabular}

Notes: Sample: 1991-2014. Analysis of stationarity conducted by means of Advanced Dickey Fuller and Phillips-Perron unit root tests. $\mu$ is the mean value, $\sigma$ the standard deviation, and C.V. the coefficient of variation of the variables.

Table 6: Properties of selected variables for the United Kingdom

\begin{tabular}{lccccc}
\hline Variable & $\mu$ & $\mu 1960-1987$ & $\mu 1988-2014$ & $\sigma$ & $C . V$. \\
\hline Public Expenditure & 0.386 & 0.387 & 0.385 & 0.03 & 0.08 \\
Interest payments & 0.069 & 0.086 & 0.057 & 0.026 & 0.37 \\
$\kappa$ & -0.016 & -0.048 & 0.005 & 0.044 & 2.75 \\
\hline Estimated Ar $(1)$ processes & \multicolumn{5}{c}{ Stationarity } \\
\hline$E_{t}=0.075+0.810 * E_{t-1}$ & & $\mathrm{I}(1)$ & $\mathrm{I}(1)$ \\
$r_{t}=0.00057+0.928 * r_{t}$ & & \multicolumn{5}{c}{} \\
\hline
\end{tabular}

Notes: Sample: 1970-2014. Analysis of stationarity conducted by means of Advanced Dickey Fuller and Phillips-Perron unit root tests. $\mu$ is the mean value, $\sigma$ the standard deviation, and C.V. the coefficient of variation of the variables.

which found a value of 0.54 from the estimated parameters of a linear regression designed to determine the average marginal tax rate from GDP growth using United States data for the period 1950-2006. This identifies the linear cost of 
Table 7: Properties of selected variables for Italy

\begin{tabular}{lccccc}
\hline Variable & $\mu$ & $\mu 1960-1987$ & $\mu 1988-2014$ & $\sigma$ & $C . V$. \\
\hline Public Expenditure & 0.382 & 0.340 & 0.426 & 0.06 & 0.15 \\
Interest payments & 0.052 & 0.042 & 0.062 & 0.028 & 0.55 \\
$\kappa$ & -0.043 & -0.144 & 0.019 & 0.078 & 1.80 \\
\hline Estimated $\operatorname{Ar}(1)$ processes & Stationarity & & & & \\
\hline$E_{t}=0.019+0.960 * E_{t-1}$ & & & $\mathrm{I}(1)$ & & \\
$r_{t}=0.00178+0.968 * r_{t}$ & & & $\mathrm{I}(1)$ & & \\
\hline
\end{tabular}

Notes: Sample: 1960-2014. Analysis of stationarity conducted by means of Advanced Dickey Fuller and Phillips-Perron unit root tests. $\mu$ is the mean value, $\sigma$ the standard deviation, and C.V. the coefficient of variation of the variables.

varying taxes in terms of the consequent losses in output growth. Similarly Barro and Redlick (2011) calculate an income multiplier of -1.1 with respect to tax revenues, which is compatible with the assumption of convex costs of taxes and suggests a value of $\alpha=0.1$. We then choose $\beta=0.01$ because it implies a ratio of stock-to-flow costs of $\frac{\beta}{\alpha}=0.1$. Finally, we choose ad hoc the specific value of the discount factor necessary to match the observed values of expenditure and debt in 2014 as steady state values of the model.

The steady-state variable values and calibrated parameter values for each country are displayed in Tables $8,9,10,11$, and 12 , where they are also compared to the data for 2014. We observe that the predicted values for taxes is very close to the observed value in most countries; with the partial exception of Japan and United Kingdom, where the steady-state level of taxes predicted by the model is above the current outcome, indicating that to stabilize debt at its current level, both countries require a substantial increase in the level of taxation.

Next we obtain a set of impulse responses for each country individually, following a one standard deviation shock to interest payments and the expenditure to GDP ratio. The United States, the United Kingdom and Germany have similar standard deviations of expenditure, of 2 to 3 percent; while in Japan and 
Table 8: Steady state values for the USA

\begin{tabular}{|c|c|c|c|c|c|}
\hline Parameter values & $\gamma=0.5$ & $\alpha=0.01$ & $\beta=0.001$ & $\kappa=0.020$ & $d=0.8555155$ \\
\hline Model steady state values & & $\mathrm{T}=0.349$ & $\mathrm{~B}=1.047$ & $\mathrm{E}=0.347$ & $r=0.037$ \\
\hline Data values & & $\mathrm{T}=0.333$ & $\mathrm{~B}=1.047$ & $\mathrm{E}=0.347$ & $r=0.037$ \\
\hline
\end{tabular}

Table 9: Steady state values for Japan

\begin{tabular}{|c|c|c|c|c|c|}
\hline Parameter values & $\gamma=0.5$ & $\alpha=0.01$ & $\beta=0.001$ & $\kappa=0.020$ & $d=0.977033$ \\
\hline Model steady state values & & $\mathrm{T}=0.406$ & $\mathrm{~B}=2.464$ & $\mathrm{E}=0.401$ & $\mathrm{r}=0.009$ \\
\hline Data values & & $\mathrm{T}=0.334$ & $\mathrm{~B}=2.464$ & $\mathrm{E}=0.401$ & $\mathrm{r}=0.009$ \\
\hline
\end{tabular}

Table 10: Steady state values for Germany

\begin{tabular}{|c|c|c|c|c|c|}
\hline Parameter values & $\gamma=0.5$ & $\alpha=0.01$ & $\beta=0.001$ & $\kappa=0.020$ & $d=0.93975138$ \\
\hline Model steady state values & & $\mathrm{T}=0.438$ & $\mathrm{~B}=0.744$ & $\mathrm{E}=0.423$ & $\mathrm{r}=0.022$ \\
\hline Data values & & $\mathrm{T}=0.439$ & $\mathrm{~B}=0.744$ & $\mathrm{E}=0.423$ & $\mathrm{r}=0.022$ \\
\hline
\end{tabular}

Table 11: Steady state values for the UK

\begin{tabular}{|c|c|c|c|c|c|}
\hline Parameter values & $\gamma=0.5$ & $\alpha=0.01$ & $\beta=0.001$ & $\kappa=0.020$ & $d=0.94197$ \\
\hline Model steady state values & & $\mathrm{T}=0.416$ & $\mathrm{~B}=0.878$ & $\mathrm{E}=0.412$ & $\mathrm{r}=0.028$ \\
\hline Data values & & $\mathrm{T}=0.380$ & $\mathrm{~B}=0.878$ & $\mathrm{E}=0.412$ & $\mathrm{r}=0.028$ \\
\hline
\end{tabular}

Table 12: Steady state values for Italy

\begin{tabular}{|c|c|c|c|c|c|}
\hline Parameter values & $\gamma=0.5$ & $\alpha=0.01$ & $\beta=0.001$ & $\kappa=0.019$ & $d=0.9214375$ \\
\hline Model steady state values & & $\mathrm{T}=0.488$ & $\mathrm{~B}=1.306$ & $\mathrm{E}=0.463$ & $\mathrm{r}=0.032$ \\
\hline Data values & & $\mathrm{T}=0.476$ & $\mathrm{~B}=1.306$ & $\mathrm{E}=0.463$ & $\mathrm{r}=0.032$ \\
\hline
\end{tabular}


Italy the standard deviation is 6 percent. Figures 2, 3, and 4 now display the responses following expenditure shocks for all the countries of the sample; and that for interest payments in one of them (the representative country, since the pattern in the latter case is very similar in all countries).

The impulse responses following an expenditure shock have a similar pattern in all countries, in that taxes and debt both display a hump-shaped reaction. That said, the responses of taxes and debt themselves are quite different from one another. Taxes rise substantially at impact, and reach a peak after a few periods. The response of debt, by contrast, has a peak after several periods and declines more slowly thereafter and follows a rather different pattern across different countries. In particular, we observe that in the United States the shock generates a peak response of debt of 10 percent after ten years, while it declines slowly afterwards to reach a net increase of roughly 5 percent after 40 years. Taxes by contrast rise rapidly and peak after five years; but, as for debt, half of the increase is still in play 40 years after the shock. The scale of the impact, however, is far smaller - roughly one tenth of that for debt, with a peak impact of just 1 percent.

The shape of the response in the other countries is similar to that in the United States, but there are also some noteworthy differences. In Japan the peak impact on debt of a shock twice as large as that in the US is only fifty percent larger (15 percent). Furthermore, the peak of debt occurs after 20 years instead of 10 . Moreover, the shock is far more persistent and hardly dies out. The impact on taxes, on the other hand, is far larger than in the USA; taxes almost immediately rise by four percentage points and then decline very slowly afterwards. Thus, notwithstanding near zero interest costs in Japan, the capacity of the country to use debt as a tool to smooth expenditure shocks is limited because the impact of spending shocks falls predominantly on taxes. 
In Germany, the impact of the shock is far smaller and less persistent; a 1.5 percent increase in spending raises debt in the same proportion on impact, with a peak soon after at 2 percent, but it dies out relatively quickly thereafter. Taxes rise very little: the initial impact is just above 0.2 percent, and it too declines immediately afterwards. Also, although Germany has a relatively high level of expenditure, spending is far less persistent than in other countries so that the impact of spending shocks is temporary and more efficiently dealt with by managing debt. In the United States and Japan, however, debt is a less efficient tool to manage expenditure shocks since they are highly persistent and debt levels are higher.

The impact of the shock in the United Kingdom is rather similar to that of Germany, albeit to a lower degree, since the shock can be efficiently absorbed by debt and because expenditure changes are not so persistent.

On the other hand, in the case of Italy, debt can only absorb fifty percent of the shock. As a result there is a larger impact on taxes and a larger increase in the stock of debt. In fact, after 20 years, debt rises by 20 percent of GDP despite an expenditure shock of 6 percent and a tax increase of 3 percent. Moreover, the impact on both taxes and debt is extremely persistent, almost permanent, because the spending changes are so persistent.

Turning now to interest payments, the impact of a one standard deviation shock to interest payments is displayed for Italy, but the pattern is very similar in all the other countries and is not reproduced in each case individually.

Here taxes rise immediately to absorb the shock, and then decline monotonically afterwards. Debt, on the other hand, declines substantially after a hump-shaped response that peaks after several years. The peculiarity of the results is the scale of the impact: the changes in taxes and debt are several times larger than the changes in GDP. This result can best be understood by 
Figure 2: Impulse response functions following a one standard deviation shock to expenditure $(\eta)$ in the USA (left), and Japan (right).
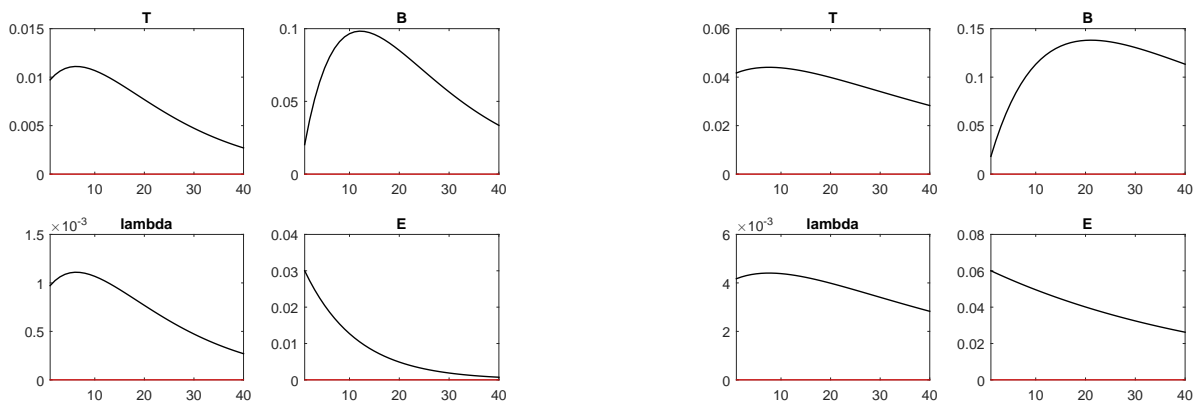

inspection of Equation 32: The steady state level of debt is extremely sensitive to interest rate variations, particularly when small values of $\alpha$ are involved, and this makes the volatility of debt less costly to the policy maker. Debt is also far less sensitive to expenditure shocks, because the variable $E$ is divided but also multiplied by a set of parameters of a similar magnitude that do not include $\alpha$. Also for positive values of $\kappa$, however small, the steady state equilibria are fragile and extremely sensitive to interest costs variations.

Figure 3: Impulse response functions following a one standard deviation shock to expenditure $(\eta)$ in the Germany (left), and the UK (right).
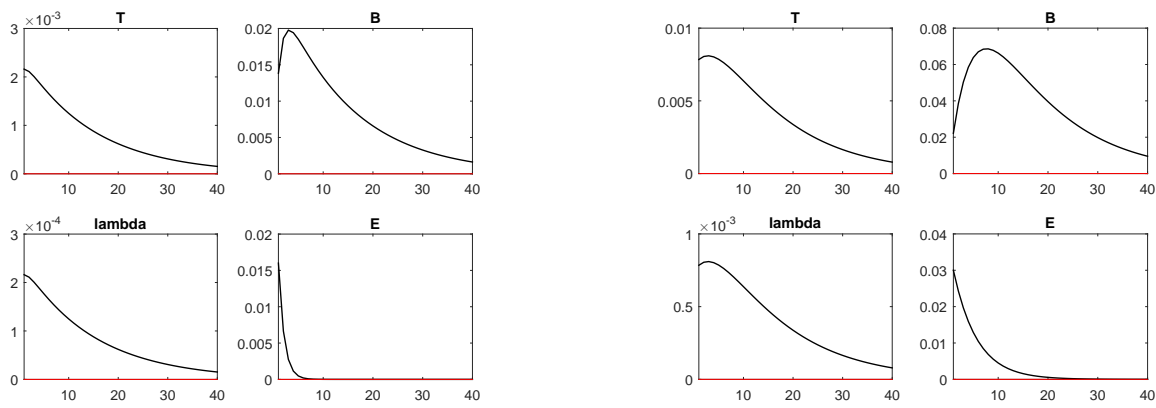

The diagrams of Figure 5 display the impulse responses obtained for the 
same interest payment shock by calibrating the model for Italy assuming a value of $\kappa=-0.043$, which is the average of the period $1960-2014$ during which Italy has cumulated its current level of debt. The only parameter that is calibrated differently from the previous exercise is the debt aversion parameter which is now set at beta $=0.02427$ to fit the data. It can be observed now that the impact of the interest costs shocks is now far more reasonable, at an increase of 2.8 percent, with a persistent stochastic process that induces a 40 percent reduction in the debt ratio matched by a similar increase of taxes. Moreover, in this case the impact of expenditure shocks is limited, as the same 6 percent shock that we observed before now generates a 3 percent peak increase in debt and is absorbed by taxes to a larger extent than in the previous case.

Figure 4: Impulse response functions following a one standard deviation shock to expenditure $(\eta)$ and interest payments $\epsilon$ in Italy.
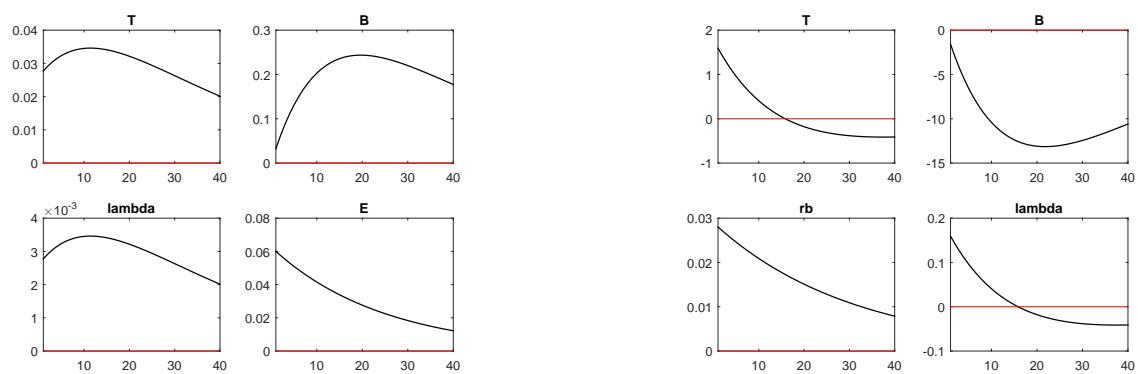

The implication of this analysis is that, although it is perfectly rational for a policymaker to cumulate a substantial amount of debt when $\kappa$ is negative, particularly when it is substantially negative as it was the case in Italy, the equilibrium outcomes become extremely fragile if $\kappa$ turns positive or zero because of a regime shift to a low inflation environment. Disinflation must be matched by fiscal discipline to keep debt stable and that effectively restricts our ability to use debt as a tool to absorb expenditure shocks - especially when 
those shocks are persistent.

Figure 5: Impulse response functions following a one standard deviation shock to expenditure $(\eta)$ and interest payments $\epsilon$ in Italy when $\kappa=-0.043$.
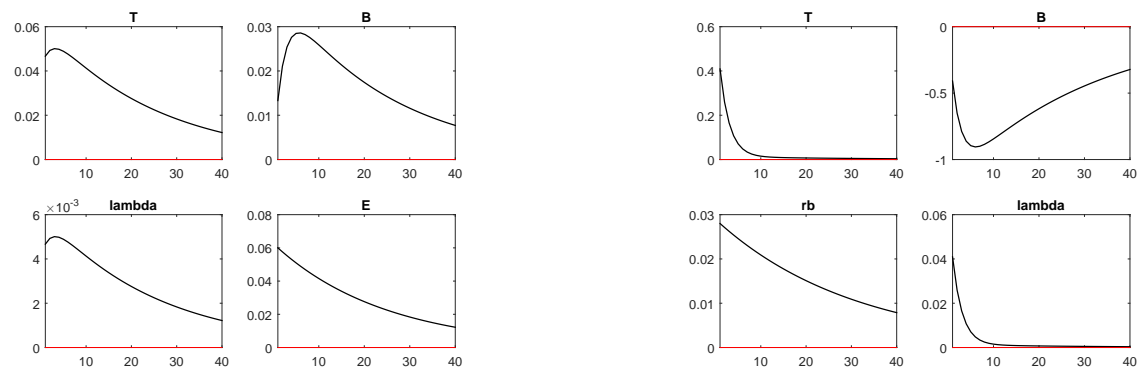

\section{Conclusion}

This paper has introduced a primary surplus rule to ensure stable and sustainable public finances in a dynamic world, and where there are entitlement spending liabilities in particular. To do so necessarily involves moving from a static formulation based on the government's period budget constraint, to a rule derived from optimizing behavior since policymakers have to trade-off their choice to use taxes now to fund current and future spending vs. the possibility of using debt (and hence future taxes) to fund that spending. Our rule therefore replaces the traditional period-by-period textbook rule. It has three important components: a) an upper limit on the growth of public spending that can be permitted relative to the growth in national income; b) the familiar growth adjusted interest payments due on current debt, but now adjusted for anticipated future primary surpluses; and c) the effects of the choice between taxing now, or later by increasing current debt.

Thus, in a dynamic context, the primary surplus needs to at least match any expected, discounted increases in public spending, the net interest on existing 
debt, and terms reflecting the preference (or cost) for extending debt relative to the cost of changing taxes. When policymakers have a strong aversion to debt ( $\beta$ is large), or if interest costs adjusted for growth are large, the primary surplus required is larger. But if the distortions due to high taxes relative to income are large, a lower primary surplus is required since debt becomes a more attractive tool to smooth spending shocks.

It is interesting to note that some countries have capped spending growth to be no more than national income growth alongside the standard primary surplus rule or a balanced structural budget, most prominently in the Eurozone's fiscal compact. But none have accounted for the impact of preferences when spending is dynamic, the projected interest payments on future deficits, or considered limiting spending growth to the available space instead of a hard cap to GDP growth (which institutionalizes austerity policies in every recession). The Euro-zone also excludes unemployment benefits and discretional spending from its rule. Thus, none of these operating rules are sufficient to guarantee fiscal sustainability. But they could be effective approximations to the full, more complicated rule. However, that remains to be determined.

Finally, outcomes for our rule calibrated to the OECD and larger national economies, produce plausible steady state results. The outcomes are all stable, although they differ from country to country and in some cases imply fiscal retrenchment to debt ratios in the $60 \%-110 \%$ range and a size of government $(G, T)$ around $40 \%-44 \%$. These outcomes vary with preference parameters and discount rate, but appear to be achievable from the current position. 


\section{References}

Auerbach, A. J., 2009. Long-term objectives for government debt. FinanzArchiv/Public Finance Analysis, 472-501.

Barro, R. J., October 1979. On the determination of the public debt. The Journal of Political Economy 87 (5), 940-971.

Barro, R. J., Redlick, C., February 2011. Macroeconomic effects from government purchases and taxes. The Quarterly Journal of Economics 126 (1), 51102.

Bohn, H., December 1990. Tax smoothing with financial instruments. The American Economic Review 80 (5), 1217-1230.

Checherita, C., Hughes Hallett, A. J., Rother., P., 2013. Fiscal sustainability using growth-maximising debt targets. Applied Economics 46 (6), 638-647.

Coricelli, F., Fiorito, R., 2013. Myths and facts about fiscal discretion: A new measure of discretionary expenditure. Documents de travail du Centre d'Economie de la Sorbonne (13033).

Davig, T., Leeper, E. M., Walker, T. B., 2010. "unfunded liabilities" and uncertain fiscal financing. Journal of Monetary Economics 57 (5), 600-619.

European Council, 2012. Towards a genuine economic and
monetary union. European Council. Brussels (available at
consilium.europa.eu/uedocs/cms_data/docs/685pressdata/131201).

Fisher, P. G., Hughes Hallett, A. J., 1988. Efficient solution techniques for linear and non-linear rational expectations models. Journal of Economic Dynamics and Control 12 (4), 635-657. 
Ghosh, A. R., Kim, J. I., Mendoza, E. G., Ostry, J. D., Qureshi, M. S., February 2013. Fiscal fatigue, fiscal space and debt sustainability in advanced economies. The Economic Journal 123 (566), F4-F30.

Hughes Hallett, A., 1979. Computing revealed preferences and limits to the validity of quadratic objective functions for policy optimization. Economics Letters 2 (1), 27-32.

Hughes Hallett, A., Hougaard Jensen, S. E., 2012. Fiscal governance in the euro area: institutions vs. rules. Journal of European Public Policy 19 (5), 646-664.

IMF, September 2009. Fiscal implications of the global and financial crisis. IMF Occasional Papers (269).

Kotlikoff, L. J., et al., 2005. Is the US bankrupt? In: 30th Annual Economic Policy Conference of the Federal reserve Bank of St. Louis. Vol. 25.

Sargent, T., 1979. Macroeconomic Theory. Academic Press, New York. 